\title{
Improving resilience of moment frames using steel pipe dampers
}

\author{
Junaedi Utomo ${ }^{1, *}$ and Antonius ${ }^{2}$ \\ ${ }^{1}$ Department of Civil Engineering, Atma Jaya Yogyakarta University, Yogyakarta, Indonesia \\ ${ }^{2}$ Department of Civil Engineering, Sultan Agung University, Semarang, Indonesia
}

\begin{abstract}
Earthquake resiliency of moment resisting frames, either new or existing ones, are important for maintaining community functionality. Improving earthquake resiliency needs a strong initiative in reducing earthquake risk. Steel pipe dampers can be used to increase earthquake resiliency. Steel pipe dampers, when installed at strategic locations in the moment frame structures, dissipate most of the earthquake energy in structures through inelastic deformation so that other components of the structure are protected. Steel pipe dampers control vibration in moment frame structures and are a disposable component in structures so that the damaged dampers can be replaced easily. Steel pipe dampers are cheap and require low workmanship, therefore the recovery time after disasters is short and the cost of recovery is low. Utilizing steel pipe dampers in passive energy dissipation systems help maintain community functionality during and after disasters. Lateral displacements were quantified and used as performance indicators. Significant drift and inter story drift reduction were achieved during a numerical study. All structural components, except the steel pipe dampers, remain elastic, indicating the effectiveness of the dampers in reducing the losses due to earthquakes.
\end{abstract}

\section{Introduction}

Earthquake resiliency of moment resisting frames, either new or existing ones, are important for maintaining their functionality. Hazards (corrosion induced damage, for example) pose continuing and significant threats to structures by reducing their capability to withstand the effect of seismic events and to recover the original functionality of the structures efficiently. Simulation to the probability of failure is necessary to evaluate components that play a dominant role in building failure [1]. Vertical steel pipe dampers are capable to dissipate most of the earthquake energy in structures through inelastic deformation so that other deteriorated components of the structure are protected. Therefore, vertical steel pipe dampers, when installed at strategic locations in the moment frame structures, can be used to improve earthquake resiliency of moment resisting frames.

\footnotetext{
*Corresponding author: utomoj@live.com
} 


\section{Vertical steel pipe dampers}

Figure 1 shows the strategy and the details of a newly developed vertical steel pipe damper. The vertical steel pipe dampers are high performance dampers capable of dissipating earthquake energy due to their high stiffness, high yield strength and large ductility as shown in Figure 2.

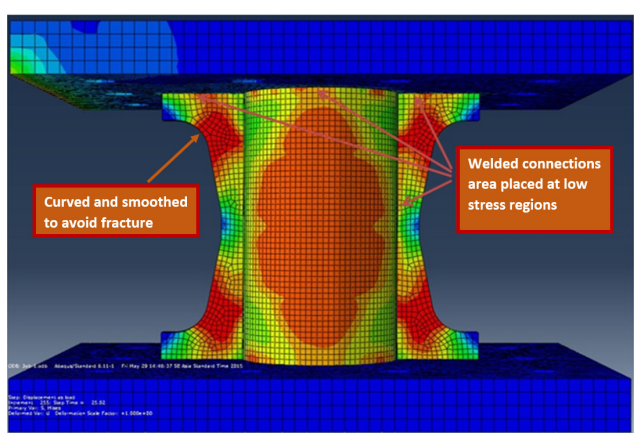

(a)

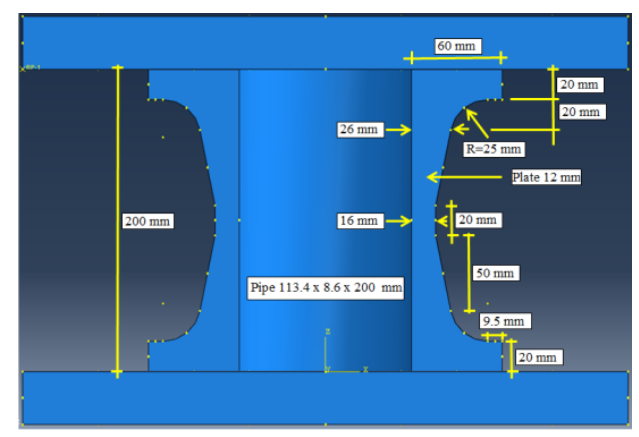

(b)

Fig 1. Vertical steel pipe damper: (a) The strategy to avoid early fracture and failure in welded connections and (b) Dimensions of the damper.

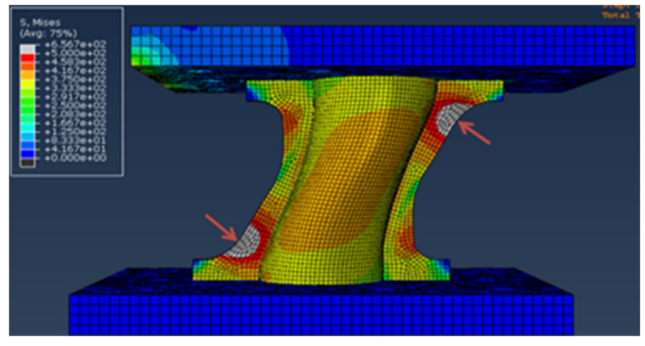

(a)

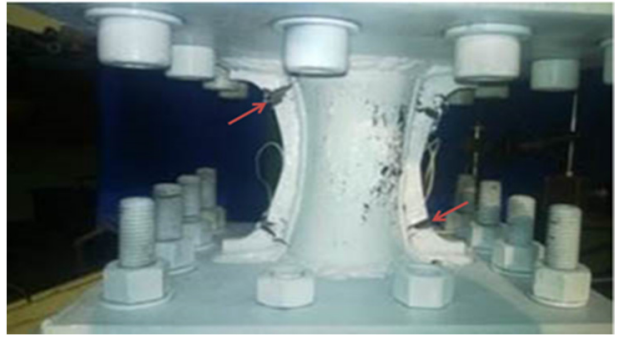

(b)

Fig 2. Vertical steel pipe damper: (a) Numerical simulation and (b) Tested specimen.

The Steel pipe dampers are disposable components in structures, hence damaged dampers can be replaced easily. Steel pipe dampers are cheap and require low workmanship, therefore the recovery time after disasters is short and the cost of recovery is low.

\section{Passive energy dissipation systems}

Passive energy dissipation systems are effective for vibration control of moment frames. Vertical steel pipe dampers provide supplemental damping that can be incorporated in both new construction and seismic retrofit applications to produce much larger equivalent damping $(\sim 30 \%)$. Passive energy dissipation systems inherently require a performance based-design approach. A new strategy based on the concept of passive structural control provide structural designers with powerful tools for performance-based design. Dynamic inelastic analysis by modeling the building as a bare frame building, neglecting possible contributions from non-structural components, was done using PERFORM-3D software [2]. 


\subsection{Dampers configuration and earthquake loadings}

A four-story steel moment resisting frame shown in Figure 3 was used to study the application of the vertical steel pipe damper. A number of end releases were applied so that the lateral load resisting systems in the building are the peripheral frames. One-way slab systems were applied to all floors. The secondary beams are not shown in Figure 3.

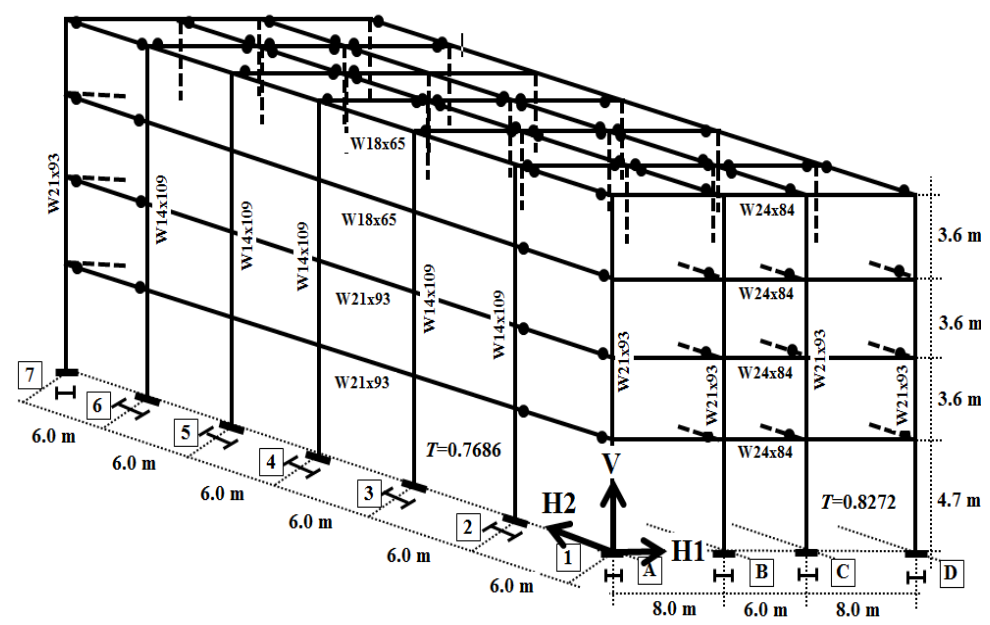

Fig. 3. Four-story steel moment resisting frame (the dampers are not shown).

The superimposed specified loads are as follows:

Gravity loading:

- Live load: Roof LL $=1.0 \mathrm{KPa}$, Floor $\mathrm{LL}=2.4 \mathrm{KPa}$

- Dead load: Floor weight plus topping $=3.6 \mathrm{KPa}$, Partitions $=1 \mathrm{KPa}$

Materials:

- Concrete: $24.0 \mathrm{MPa}$

- Reinforcing steel: ASTM A572 steel, grade $50 f_{y}=345 \mathrm{MPa}$

Elements dimension:

- Exterior columns: W21x93 (along H1), and W14x109 (along H2)

- Interior columns: W12x72 (along H2)

- Exterior beams: W24x84 (along H1), W21x93 and W18x95 (along H2)

- Interior beams: W24x84 (along H1), W21x93 and W18x95 (along H2)

Fundamental periods:

- $T=0.8272$ seconds (along $\mathrm{H} 1$ )

- $T=0.7689$ seconds (along H2)

The configuration of the dampers in the peripheral frames along $\mathrm{H} 1$ and $\mathrm{H} 2$ are shown in Figure 4 . The required number of dampers in each story had been estimated using the energybased method proposed by Benavent-Climent [3]. The required lateral stiffness and lateral strength of the damper for near-fault ground motion were determined from input energy spectra for moderate-seismicity regions proposed by Benavent-Climent et al. [4]. Auxiliary structures in the form of triangular bracings are needed to install dampers between two points where large relative motion exists during earthquakes. Auxiliary structures shown in Figure 4 were chosen to minimize the influence of axial forces to the dampers. When the dampers yield, they lose their stiffness. The presence of the axial forces when the dampers dissipate energy reduce the effectiveness of the dampers as shown in Figure 5. 


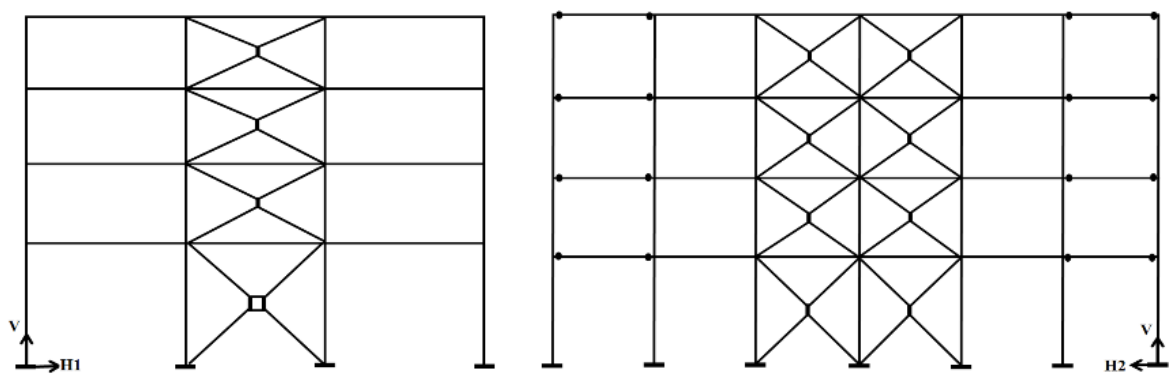

(a)

(b)

Fig. 4. Configuration of the dampers in peripheral frames: (a) Two peripheral frames along H1, and (b) Two peripheral frames along $\mathrm{H} 2$.

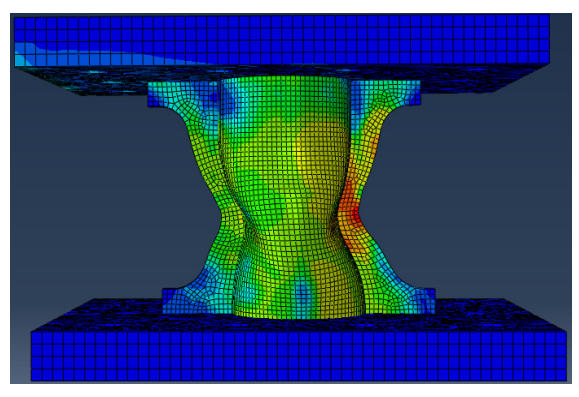

(a)

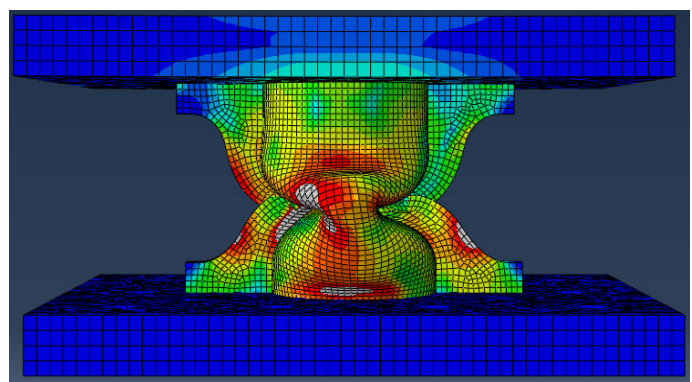

(b)

Fig. 5. Influence of axial forces when dampers dissipate energy: (a) Small axial force and (b) Large axial force.

Four earthquakes with different characteristics were chosen for numerical simulation. The steel dampers installed in the moment resisting frames (see Figure 4) are part of the passive energy dissipation system. The chosen earthquake accelerograms were the N-S component of El-Centro 1940, Fukushima Hamadori 2011 (ABSH13 station), Padang 2009 and Chi Chi 1999 (CHY028 station). Peak Ground Acceleration (PGA) of El-Centro 1940 is the lowest. The PGA of the other three accelerograms were scaled down to the PGA of El-Centro 1940 $(0.3129 \mathrm{~g})$.

\subsection{Results of the simulation study}

The analytical model of the four-story steel moment resisting frame shown in Figure 4 was developed using the PERFORM-3D software. Test result data of the vertical steel pipe damper were used to model shear vs. lateral displacement of the damper. The seismic isolator component in PERFORM-3D was used to model the damper as shown in Figure 6. Nonlinear dynamic analysis was done for moment resisting frames without and with dampers. The interstory drifts for moment resisting frames without and with dampers are shown in Figure 7. Comparing Figure $7 \mathrm{a}$ and Figure $7 \mathrm{~b}$ it can be seen that the inter-story drifts were reduced significantly due to the presence of dampers in the moment resisting frame. The dissipated strain energy of each component of the moment resisting frame with dampers is shown in Table 1. Only the vertical steel pipe dampers dissipate energy. All other components except the dampers remain elastic. The presence of the dampers installed at strategic locations in the four-story steel moment frame were able to protect the structure against strong earthquakes. 
Extensive yielding in dampers is the energy dissipation mechanism. By dissipating inelastic energy, the dampers control the vibration of the structure during strong earthquakes.

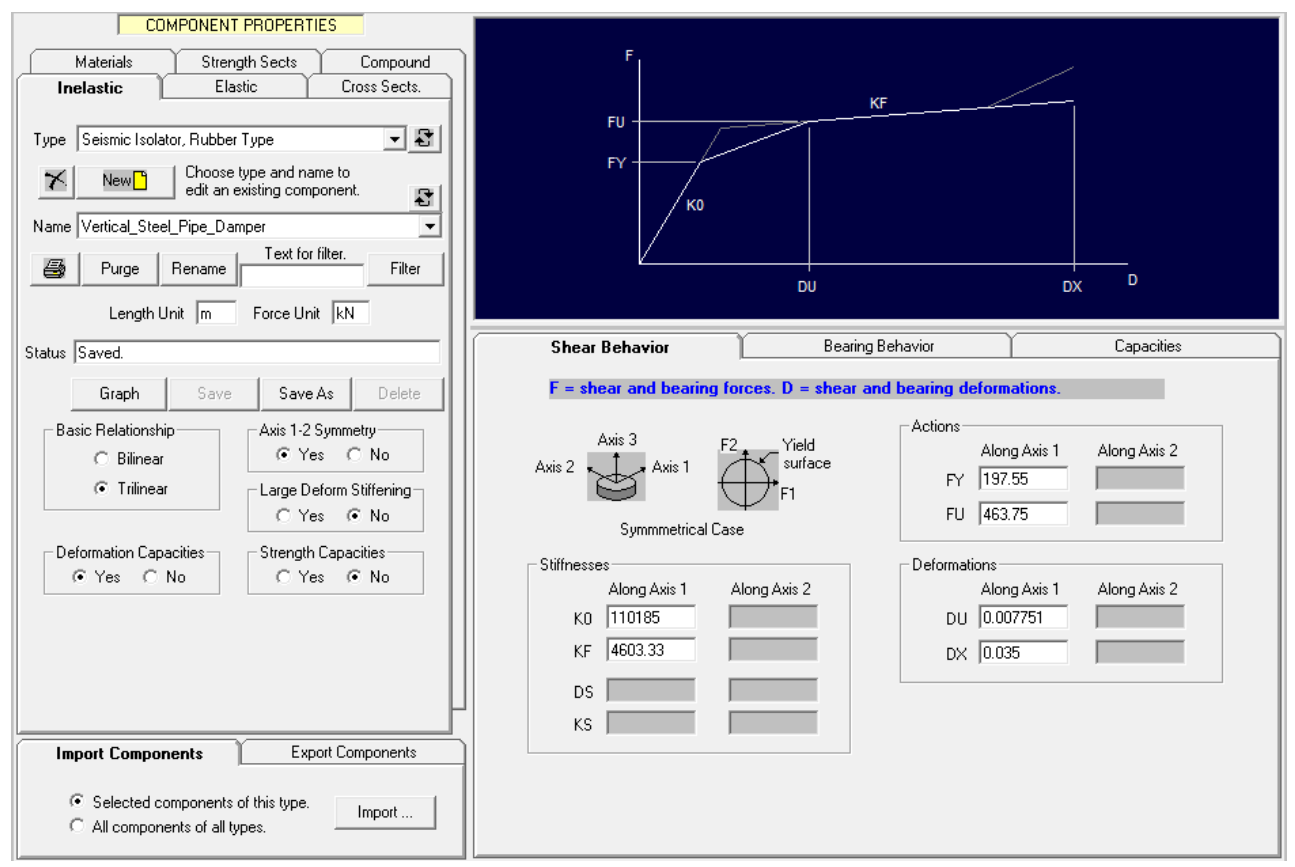

Fig. 6. Trilinear model of the force vs. displacement of the vertical pipe damper.

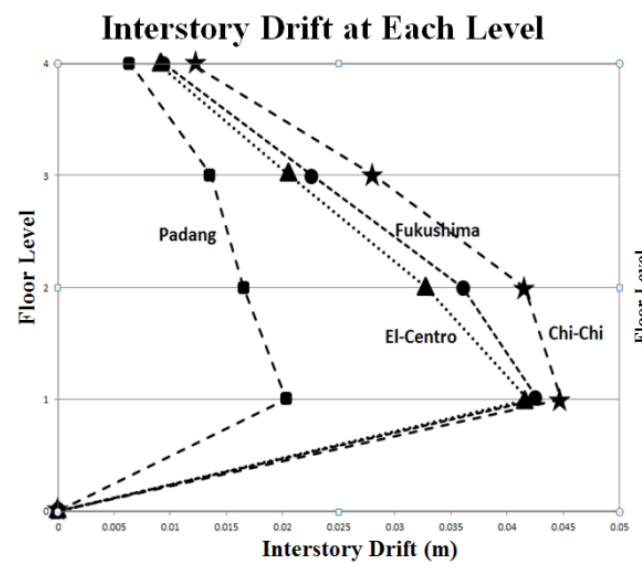

(a)

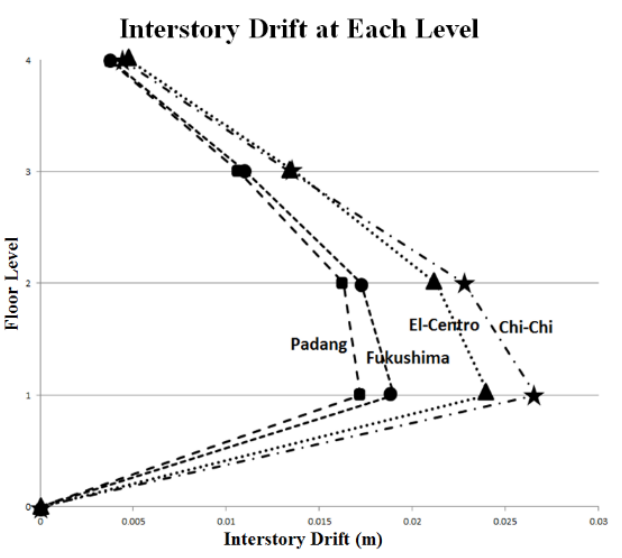

(b)

Fig. 7. Inter-story drift due to four earthquakes: (a) Frame without dampers and (b) Frame with dampers. 
Table 1. Dissipated inelastic energy in kN.m at each component of the peripheral frames along H1.

\begin{tabular}{|c|c|c|c|c|}
\cline { 2 - 5 } \multicolumn{1}{c|}{} & \multicolumn{4}{c|}{ Earthquake } \\
\hline Group name & $\begin{array}{c}\text { El-Centro - } \\
\mathbf{1 9 4 0}\end{array}$ & $\begin{array}{c}\text { Fukushima - } \\
\mathbf{2 0 1 1}\end{array}$ & $\begin{array}{c}\text { Padang - } \\
\mathbf{2 0 0 9}\end{array}$ & $\begin{array}{c}\text { Chi-Chi - } \\
\mathbf{1 9 9 9}\end{array}$ \\
\hline Perimeter Columns & 0 & 0 & 0 & 0 \\
\hline Perimeter Beams & 0 & 0 & 0 & 0 \\
\hline Interior Columns & 0 & 0 & 0 & 0 \\
\hline Interior Beams & 0 & 0 & 0 & 0 \\
\hline Connection Panel Zones - along H1 & 0 & 0 & 0 & 0 \\
\hline Connection Panel Zones - along H2 & 0 & 0 & 0 & 0 \\
\hline Vertical Steel Pipe Dampers & 261.49 & 422.4 & 202.35 & 233.29 \\
\hline Bracing HSS-H1-1st floor & 0 & 0 & 0 & 0 \\
\hline Bracing HSS-H2-1st floor & 0 & 0 & 0 & 0 \\
\hline Bracing HSS-H2-other floors & 0 & 0 & 0 & 0 \\
\hline Bracing HSS-H1 other floors & 0 & 0 & 0 & 0 \\
\hline Total for All Groups & 261.49 & 422.4 & 202.35 & 233.29 \\
\hline
\end{tabular}

Figure 8 shows four of the time histories of energy dissipation due to the Chi-Chi 1999, Padang 2009. El-Centro 1940 and Fukushima 2011 earthquakes. The strain and kinetic energies due to the four earthquakes diminish quickly when the dampers start yielding. Therefore, the strain and kinetic energy are not shown in Figure 8. Four graphs showing inelastic energy to input energy ratio (Eh/Eir) time histories of the four earthquakes above indicate that the inelastic energy dissipation is stable for each earthquake. The inelastic energy to maximum inelastic energy ratio $\left(E h / E h \_m\right)$ of the Chi-Chi and Padang earthquakes indicate that the maximum dissipated inelastic energy for both earthquakes was reached quickly.

\section{Inelastic Energy to Input Energy Ratio and Maximum Inelastic Energy}

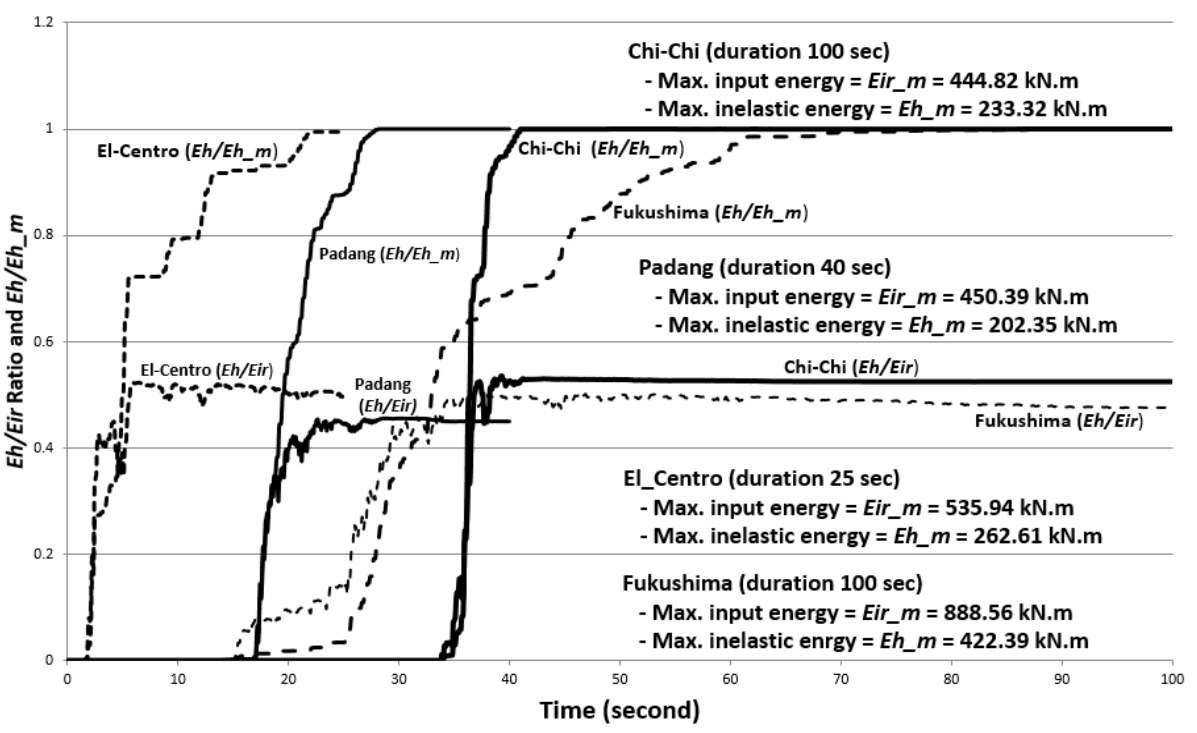

Fig 8. Time histories of energy dissipation due to Chi-Chi 1999, Padang 2009, El-Centro 1940 and Fukushima 2011 earthquakes. 


\section{Improving physical resilience of moment resisting frames}

Time invariant capacity design criteria that do not account for environmental hazards is currently used for seismic design of moment frames. As shown in Figure 9, hazards (corrosion induced damage and earthquakes) pose continuing and significant threats to structures by reducing the capability to withstand the effect of seismic events and to recover to the original functionality of the structures efficiently. In Figure 9, moderate, strong and very strong earthquakes were assumed to happen in succession starting from moderate earthquake.

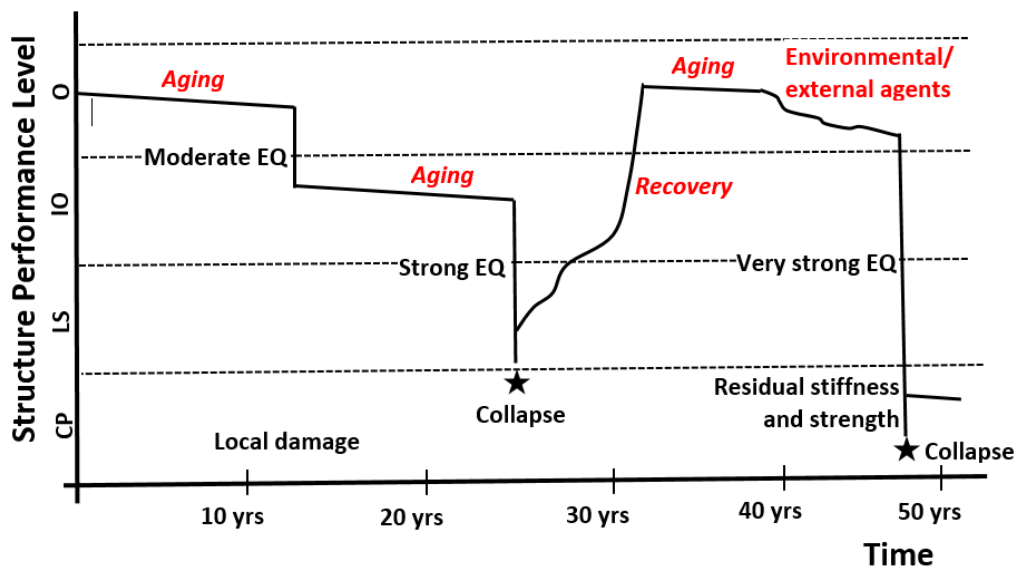

Fig. 9. Hazards pose continuing and significant threats to structures.

Earthquake resiliency of moment resisting frames, either new or existing ones, are important for maintaining their functionality. Steel pipe dampers can be used to increase earthquake resiliency. If steel pipe dampers are installed at strategic locations, they can reduce inter-story drifts up to $40 \%$ as shown in Figure 7. Significant reduction of inter-story drifts reduces the failure probability and increases the physical resilience of moment resisting frames. Significant reduction of inter-story drifts protects the structural and non-structural components in moment resisting frames as shown in Table 1. Steel pipe dampers are disposable components in moment resisting frames. Yielding dampers are designed to dissipate earthquake energy in a stable manner as shown in Figure 8. Damaged dampers can be replaced easily, therefore the time required to restore the normal level of functional performance of the system (the time of recovery) is short. Steel pipe dampers are cheap and require low cost workmanship therefore the financial and labor (the resourcefulness) required to restore the normal level of functional performance of the system are low.

Fragility curves are defined as the probability of reaching or exceeding a specific damage state under earthquake excitation. The effects of resourcefulness and recovery phase on the fragility curve due to an event of intensity $I_{1}$ is shown in Figure 10. Figure 10a shows the recovery phase at different instants between $t_{o}$ and $t_{l}$ and Figure 10b illustrates how structure repair (damaged dampers replacement) shifts the fragility curve back to the original condition before the instant $t_{o}$, and finally attained at $t_{1}$ [5]. The time of recovery depends on the angle $\theta$ in Figure 10a (a large angle $\theta$ indicates short recovery time). Damage in moment frames are concentrated in steel pipe dampers. Because dampers are disposable components in moment frames, the angle $\theta$ is large meaning the recovery time is short. Because the steel pipe dampers are cheap and require low cost workmanship, the cost to bring back structure to pre-event condition is low. 

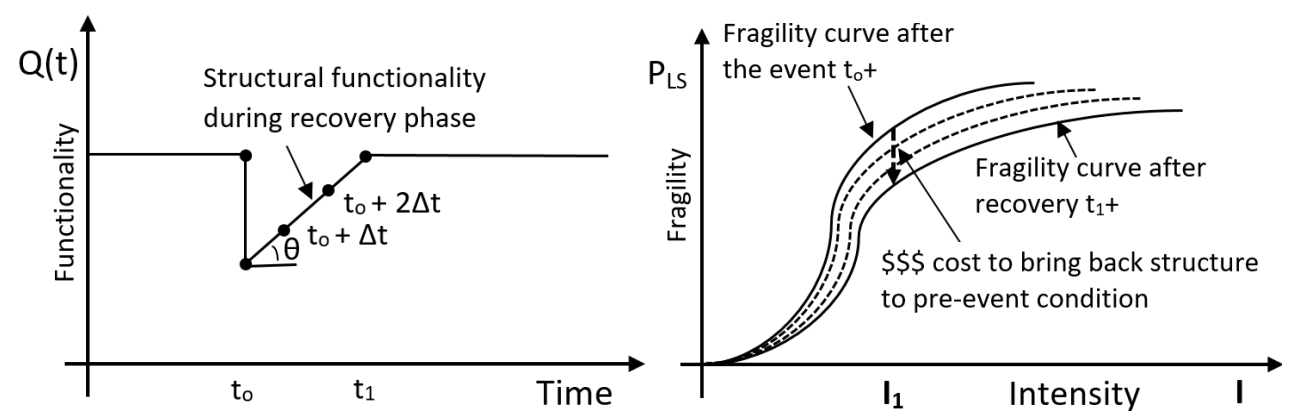

Fig. 10. Effects of resourcefulness and recovery phase on fragility curve: a) Functionality; b) Fragility curve [5].

The results of nonlinear dynamic analysis indicated that the installation of the dampers increase the story shears, member forces around the dampers and the floor accelerations. This is the drawback of all metallic dampers, including steel pipe dampers. Some nonstructural elements and components are vulnerable to excessive acceleration. Therefore, floor acceleration needs to be limited. To tackle this problem, metallic dampers can be installed in parallel with viscous dampers. The damping forces from viscous dampers are 90 degrees out of phase with displacement driven forces in the moment frames. Metallic dampers reduce lateral displacement while viscous dampers reduce acceleration demands. The combined effect of steel pipe dampers and any viscous dampers was not studied in this numerical simulation.

\section{Conclusion}

Simulation study to the performance of moment resisting frames equipped with steel pipe dampers under seismic excitation had been conducted. Although the use of steel pipe dampers improves the resiliency (reduces the overall earthquake response) of the moment frames, the installation of steel pipe dampers increases story shears, member forces around the dampers and floor accelerations. Steel pipe dampers were found effective in reducing lateral displacement demands, and the increase of floor accelerations could be reduced by installing viscous dampers in parallel with steel pipe dampers.

\section{References}

1. J. Widodo S., T. Joko Wahyu. A. and N. Anwar, Int. J. Eng. Technol. Innov., 6, 4, 264273 (2016)

2. G. H. Powel, User Guide Perform-3D Version 5 - Nonlinear Analysis and Performance Assessment for 3D Structures, Computer and Structures Inc., California (2011)

3. A. Benavent-Climent, Soil Dynamics and Earthquake Engineering, 31, 1385-1396 (2011)

4. A. Benavent-Climent, L. G. Pujades and F. Lopez-Almanza, Earthquake Engng Struct. Dyn., 31, 1151-1172 (2002)

5. A. Caverzan and G. Solomos, JRC Science and Policy Report, European Commission (2014) 